\section{In vitro reappraisal of the pulmonary artery catheter balloon volume-pressure rela- tionship: comparison of four different catheters}

Shigemasa lkeda MD, ${ }^{*}$ Keiichi Yagi MD, ${ }^{*}$

John F. Schweiss MD, ${ }^{*}$ Sharon M. Homan PhD $\dagger$
The most serious risk of the use of the flow-directed pulmonary artery $(P A)$ catheter is $P A$ rupture due to high balloon inflation pressure of the catheter. Previously reported measurements of $P A$ catheter intra-balloon pressure and volume during balloon inflation were performed mostly in a static fashion, that is, measurements were performed after a cerrain volume of air had been injected into the balloon. In this study, simultaneous measurements of pressure and volume, in addition to a static study, were performed in vitro using four PA catheters (Abbott Opticath, Arrow Hands-Off, Baxter Edwards and Spectramed). The peak intra-balloon pressure was recorded immediately before loss of resistance was felt in the inflating syringe. Contrary to previously reported studies, the peak intra-balloon pressure was not the pressure exerted on the pulmonary artery wall unless the tip of the catheter was already in the peripheral pulmonary artery. The loss of resistance volume which was constant for each catheter could be used reliably as an indicator of instantaneous balloon inflation. The slower the rate of injection, the lower were the peak pressure and the injection volume at the peak pressure. The Abbott, Edwards and Spectramed catheters had similar characteristics of inflation volume and intra-balloon pressure. The Arrow catheter had

\section{Key Words}

EQUIPMENT: catheters, pulmonary artery;

MEASUREMENT TECHNIQUES: pulmonary arterial.

From the Departments of Anesthesiology* and Public Health, $†$ St. Louis University School of Medicine, St. Louis, Missouri.

Address correspondence to: Dr. Shigemasa Ikeda, Department of Anesthesiology, St. Louis University School of Medicine, 3635 Vista Avenue at Grand Boulevard, P.O. Box 15250, St. Louis, Mo. 63110-0250

Accepted for publication 22nd February, 1991. higher balloon opening and plateau pressures, and a smaller balloon volume compared with the other three catheters.

Le risque le plus sérieux lors de l'utilisation du cathéter de l'artère pulmonaire dirigé à l' aide du flux sanguin est la rupture de l'artère pulmonaire causée par une pression d'insufflation élevée du ballonnet. Les mesures déjà publiées du volume et de la pression à l'intérieur du ballonnet du cathéter de l'artère pulmonaire lors de l'insufflation du ballonnet ont surtout été prises dans une situation statique, $c^{\prime}$ est-à-dire que les mesures étaient prises après qu'un certain volume d'air ait été injecté dans le ballonnet. Dans la présente étude, des mesures simultanées de la pression et du volume, en plus d'une étude en condition statique, ont été prises in vitro en utilisant quatre cathéters de lartère pulmonaire (Abbot Opticath, Arrow Hands-Off, Baxter Edwards et Spectramed). La pression maximum dans le ballonnet était mesurée immédiatement avant la perte de résistance sentie avec la seringe utilisée pour l' insufflation. Contrairement aux études déjà publiées, la pression de pointe dans le ballonnet ne correspondait pas à la pression exercée sur les parois de l'artère pulmonaire sauf si le bout du cathéter se trouvait déjà dans l'artère pulmonaire périphérique. Le volume auquel la perte de résistance etait sentie et qui était constant pour chaque cathéter, pourrait être utilisé de façon fiable comme indicateur de l'insufflation instantannée du ballonnet. Plus la vitesse d'injection était lente, plus on observait des pressions de pointe et des volumes d'injection à la pression de pointe qui était bas. Les cathéters Abbott, Edwards et Spectramed avaient des caractéristiques semblables de volume de gonflement et de pression dans le ballonnet. Le cathéter Arrow avait des pressions de plateau et d'ouverture du ballonnet plus élevées et un volume du ballonnet plus petit comparativement aux trois autres cathéters.

Pulmonary artery rupture is one of the most serious complications of the use of the flow-directed PA catheter. 
Several risk factors have been reported for catheterinduced PA rupture. ${ }^{1}$ One of these is that inflation of the balloon may require high pressure. Changes in a PA catheter intra-balloon pressure during inflation have been reported previously, ${ }^{2-5}$ but the reported measurements were performed mostly in a static fashion, that is, changes in pressure were measured after a certain volume of air had been injected into the balloon. Simultaneous measurement of the intra-balloon pressure, injected air volume and balloon volume has not been reported. In this study, measurements of intra-balloon pressure, injected air volume and balloon volume have been performed simultaneously during balloon inflation to show changes in the pressure and volume in a dynamic fashion using four different commercially available PA catheters.

The static relationship between the injected air volume and the balloon pressure or volume was also studied after injection of increasing incremental volumes of air, to determine if there were any differences in pressure and volume characteristics among different brands of PA catheters. Changes in the PA catheter pressure and volume in a simulated PA capillary wedged position were also studied.

\section{Methods}

The commercially available PA catheters used in this study were Abbott Opticath P7110 (Mountain View, CA), Arrow Hands-Off (Reading, PA), Baxter Edwards 94A-131H-7F (Irvine, CA) and Spectramed SP5107H (Oxnard, CA). The size of the catheters studied was 7.0 French, except for 7.5 French Abbott Opticath. Five catheters of different lot numbers were selected from each of the four manufacturer's products. Each catheter was subjected to five inflations at different rates as dynamic and static studies. Measurements of the pressure and volume were performed initially in a constant temperature water bath maintained at $37^{\circ} \mathrm{C}$ and at room temperature. There were no differences in both pressure and volume at either temperature. Subsequent measurements were performed at room temperature.

\section{Dynamic study}

Simultaneous measurements of the intra-balloon pressure, injected air volume, and balloon volume were studied in a dynamic fashion during continuous air injection using five PA catheters from each of the four manufacturers. Air, $1.5 \mathrm{ml}$, was injected over $0.5,1,2.5$, 3,4 or $6 \mathrm{sec}$. Injection speeds were randomized for each catheter.

The intra-balloon pressure was measured by a pressure transducer. Both injected air and balloon volumes were measured by water displacement using an ultrasonic flow probe (Transonic System, 2N In Line cannulating probe,

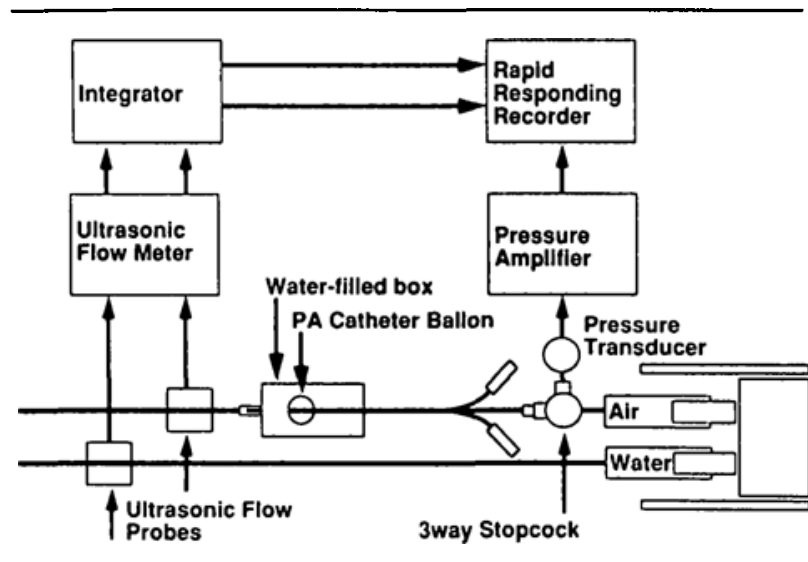

FIGURE 1 A diagram of the experimental set-up.

Ithaca, NY) and an ultrasonic flowmeter (Transonic System T201, Ithaca, NY). The integrated volume was recorded simultaneously with the pressure (PPG Biomedical System, Analog data processor ADV-23, Pittsburgh, PA). The pressure transducer, the ultrasonic flow probe and the pulmonary artery balloon were placed on the same level for pressure and volume measurements (Figure 1).

\section{Static study}

The intra-balloon pressure and balloon volume were measured in a static fashion following incremental injections of $0.1 \mathrm{ml}$ of air to a total volume of $1.5 \mathrm{ml}$. In another experiment, the intra-balloon pressure was measured in a similar way using the same catheters which were inserted into four different sizes of glass tubes, the internal diameter of which was $2.8,3.9,5.9$ and $8.2 \mathrm{~mm}$. This experiment examined the relationship between intraballoon pressure and injected air volume in the different diameter which imitated the pressure changes in a wedged position.

Statistically significant differences among groups were determined using one-way ANOVA. The Tukey's method of post-hoc comparisons was used to identify individual differences between groups in the dynamic study. All pairwise comparisons in the static study were performed by adjusting the numbers of comparisons using the Bonferonni method.

\section{Results}

\section{Dynamic study}

Representative pressure and volume changes during continuous inflation of the balloon are shown in Figure 2. Similar volume and pressure relationships were observed in all tested catheters. The peak pressure and the injected air volume at the peak pressure decreased with slower rate of injection. The injection volume of the Edwards catheter 


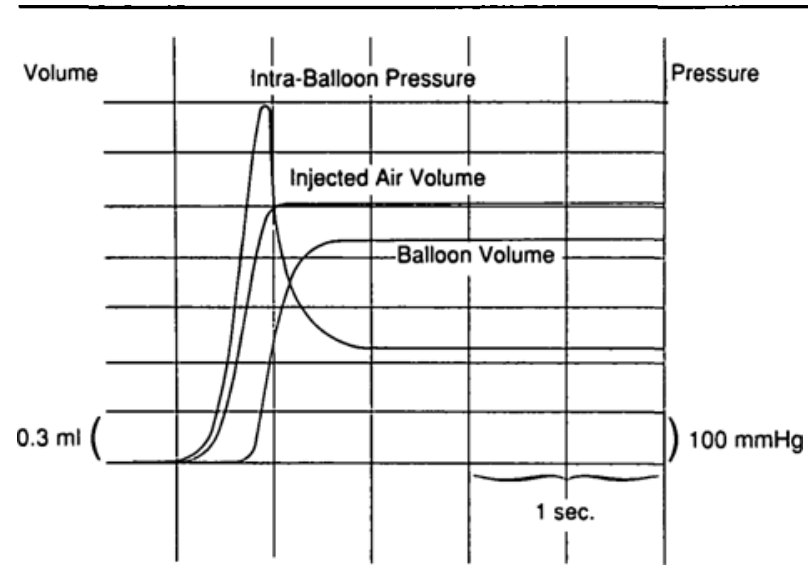

FIGURE 2 Simultaneous measurement of the intra-balloon pressure, the balloon volume and the injected air volume during continuous inflation of the balloon using the Edwards PA catheter. *The peak intra-balloon pressure. $t$ The plateau pressure.

at the peak pressure was constant at $1.1 \mathrm{ml}$ when the injection time exceeded $2.5 \mathrm{sec}$ (Table I). Statistical analysis by ANOVA confirmed differences in the peak pressure and the injected air volume at the peak pressure.

The decreasing peak pressure and the constant plateau pressure with increasing injection times were observed similarly in all catheters. However, the Spectramed and the Arrow catheters had significantly higher peak pressures than the Edwards and Abbott catheters. There were no differences in the peak pressure between the Edwards and the Abbott catheters. The Arrow catheter had a higher plateau pressure compared with the other three catheters. Among the other three catheters there were no statistical differences in the plateau pressures regardless of speed of air injection.

\section{Static study}

In the static study each catheter had a slightly different

TABLE I Relationships of the speed of balloon inflation to the peak and plateau pressures, and the injected volume at the peak pressure during continuous inflation of the Edwards PA catheter

\begin{tabular}{llll}
\hline $\begin{array}{l}\text { Injection time* } \\
(\text { sec. })\end{array}$ & $\begin{array}{l}\text { Peak balloon } \\
\text { pressure } \\
(\mathrm{mmHg})\end{array}$ & $\begin{array}{l}\text { Plateau pressure } \\
(\mathrm{mmHg})\end{array}$ & $\begin{array}{l}\text { Injected volume at } \\
\text { peak pressure } \\
(\mathrm{ml})\end{array}$ \\
\hline 0.5 & $688 \pm 20$ & $224 \pm 10$ & $1.4 \pm .02$ \\
1.0 & $555 \pm 17$ & $224 \pm 10$ & $1.3 \pm .03$ \\
2.5 & $442 \pm 14 \dagger$ & $224 \pm 10$ & $1.1 \pm .02 \dagger$ \\
3.0 & $419 \pm 9 \dagger$ & $224 \pm 3$ & $1.1 \pm .02 \dagger$ \\
4.0 & $412 \pm 10 \dagger$ & $224 \pm 3$ & $1.1 \pm .02 \dagger$ \\
6.0 & $405 \pm 9 \dagger$ & $224 \pm 3$ & $1.1 \pm .02 \dagger$ \\
\hline
\end{tabular}

Values are mean $\pm \mathrm{SD}$.

*Time to inject $1.5 \mathrm{ml}$ of air.

† Statistically significant difference from baseline measurement at $0.5 \mathrm{sec}$ injection time.

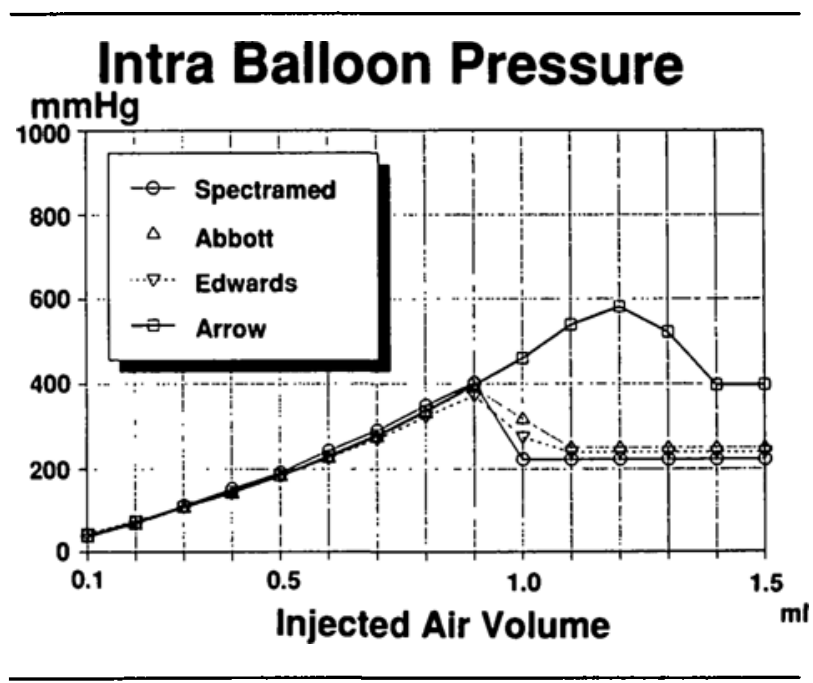

FIGURE 3 The intra-balloon pressure measured in a static fashion following increasing increments of $0.1 \mathrm{ml}$ of air being injected. Plateau pressure for the Arrow catheter is higher than that for each of the other three catheters.

opening volume (Table II) (the injected air volume at which the balloon started to inflate), but the standard deviation was 0 for all of the opening volumes. The plateau pressure of the Arrow catheter was higher than those of the other three catheters. Changes in the intra-balloon pressure following increments of $0.1 \mathrm{ml}$ of injected air were shown in Figure 3.

Figure 4 shows the relationships between injected air volume, intra-balloon pressure and the diameter of the glass tube into which the catheters were inserted. In the unrestricted balloon, which is shown in the front of each figure, the peak pressure was attained when $0.9 \mathrm{ml}$ of air was injected in the case of the Abbott, Edwards and Spectramed catheters and this occurred in the Arrow catheter at $1.2 \mathrm{ml}$. With continued injection of air the pressures began to decrease and reached a plateau after an additional $0.2 \mathrm{ml}$ was added. When the catheters were placed within the glass tube whose diameters were 2.8 and $3.9 \mathrm{~mm}$, the balloon pressure increased linearly with the injected air volume, and the pressure exceeded 700 $\mathrm{mmHg}$.

\section{Discussion}

In a previous study, ${ }^{2}$ balloon inflation was measured after a certain volume of air had been injected into the balloon and the highest pressure obtained was reported as a potential pressure exerted against the pulmonary arterial wall. In the dynamic study shown in Figure 2, the balloon was barely inflated at the peak pressure. The measured peak pressure was the pressure inside the balloon, and did not show the pressure exerted against the wall of PA. This finding is contrary to the previously reported studies. ${ }^{2,3}$

A rapid decrease in balloon pressure was observed 


\section{Arrow}

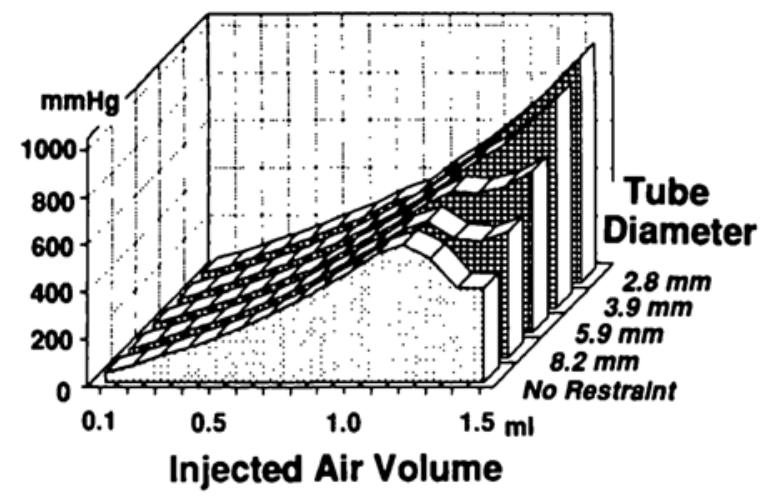

Abbott

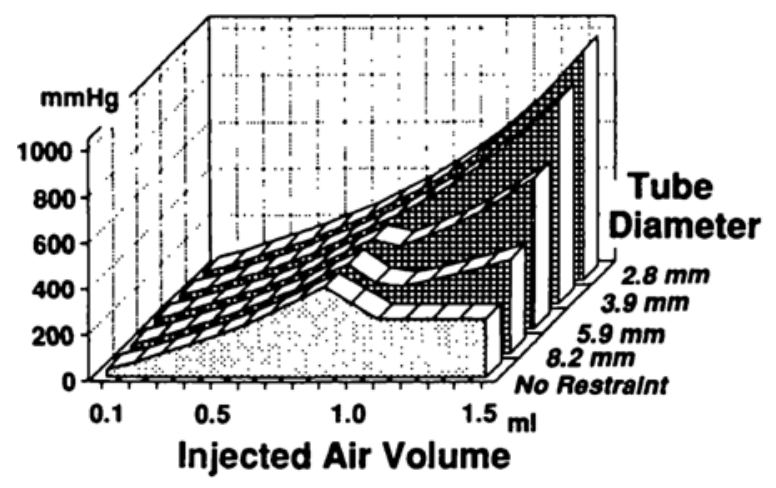

Edwards

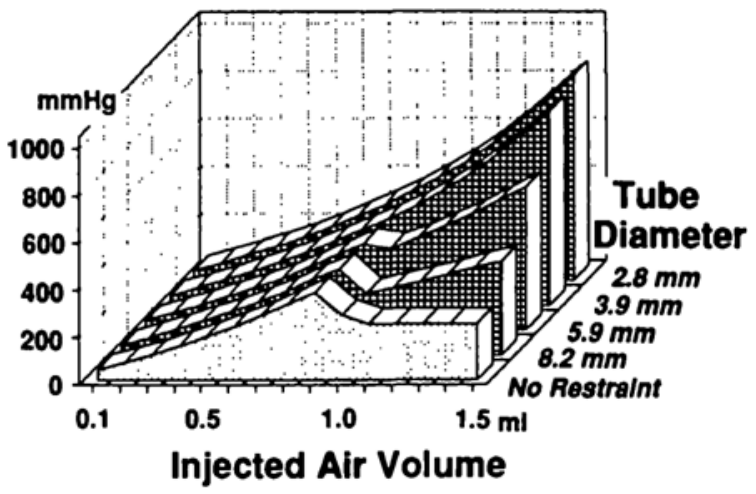

Spectramed

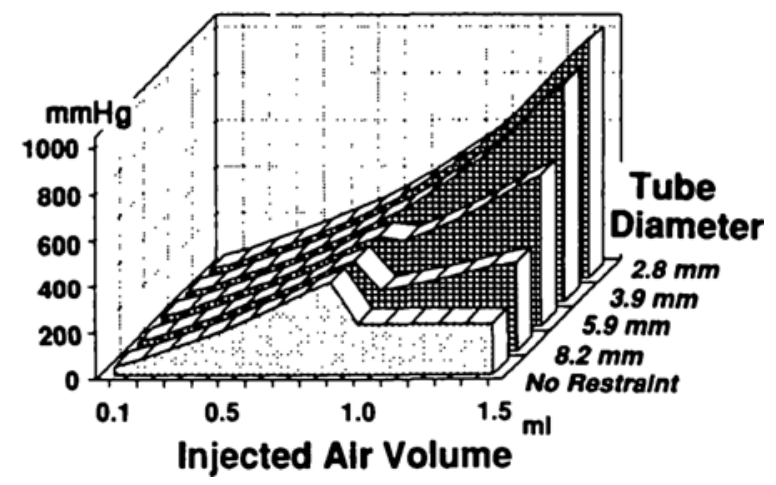

FIGURE 4 Intra-balloon pressures following increments of $0.1 \mathrm{ml}$ of air with the catheters inserted into the four different sizes of glass tubes with internal diameter 2.8 to $8.2 \mathrm{~mm}$. The pressures shown at the front of each is the pressure obtained without inserting catheter into the glass tubc.

TABLE II The volumes and pressures obtained in the static study

\begin{tabular}{lllllr}
\hline Catheters & $\begin{array}{l}\text { Opening } \\
\text { volume } \\
(\mathrm{ml})\end{array}$ & $\begin{array}{l}\text { Maximal } \\
\text { volume } \\
(\mathrm{ml})\end{array}$ & $\begin{array}{l}\text { Opening } \\
\text { pressure } \\
(\mathrm{mmHg})\end{array}$ & $\begin{array}{l}\text { Plateau } \\
\text { pressure } \\
(\mathrm{mmH})\end{array}$ & $\begin{array}{r}\text { Maximal } \\
\text { pressure } \\
(\mathrm{mmHg})\end{array}$ \\
\hline Abbott & 0.8 & $1.01 \pm 0.44$ & $409 \pm 29$ & $250 \pm 20$ & $987 \pm 17$ \\
Arrow & 1.0 & $.78 \pm 0.19$ & $643 \pm 99$ & $397 \pm 35$ & $950 \pm 55$ \\
Edwards & 0.8 & $1.01 \pm 0.16$ & $383 \pm 24$ & $239 \pm 7$ & $865 \pm 13$ \\
Spectramed & 0.7 & $1.08 \pm 0.22$ & $402 \pm 6$ & $222 \pm 6$ & $1054 \pm 20$ \\
\hline
\end{tabular}

Values are mean \pm SD.

Opening volume: volume of air injected when balloon stared to inflate.

Maximal volume: intra-balloon volume when $1.5 \mathrm{ml}$ of air was injected.

Opening pressure: pressure at which balloon started to inflate.

Plateau pressure: pressure when intra-balloon pressure reached a stable level.

Maximal pressure: intra-balloon pressure when $1.5 \mathrm{ml}$ of air was injected after a catheter was inserted into a

glass tube with an internal diameter of $2.8 \mathrm{~mm}$.

when a loss of resistance was felt in the syringe during injection of the remaining volume, and the balloon pressure reached the plateau pressure. Changes in the peak and plateau pressures in this dynamic study were essentially similar to those reported by Durbin. ${ }^{5}$ In his study a slower inflation (over one to two seconds) did not result in a lower peak pressure. However, in this study the slower injection of air (over 2.5 to $6 \mathrm{sec}$ ) resulted not only in a lower peak pressure, but ultimately a lower balloon volume (Table I), and possibly a lower pressure against 
the wall of PA in vivo, although the plateau pressure measured in vitro was constant regardless of the injected speed. Using the 7 French Edwards catheter, McDonald et al. reported a similar finding. ${ }^{2}$ In their study the peak pressure was reported at the injection volume of $1 \mathrm{ml}$. Differences between their study and the present one, which are clinically insignificant, are probably due to the different method used to inject air (increments of $0.25 \mathrm{ml}$ in their study vs continuous in this study). If the air was injected over three seconds or longer, the peak pressure and the volume of injected air at the peak pressure did not change in all four catheters.

In the static study, the plateau pressure of the Arrow catheter was higher than those of the other three catheters. Though the opening pressure of the Arrow was higher than the other four catheters, no statistical differences were observed with any of the other catheters, due to the high variability in the Arrow catheter. There were no differences in both opening intra-balloon and plateau pressures among the other catheters (Table II and Figure 3). When $1.5 \mathrm{ml}$ of air was injected, the Arrow catheter had the smallest balloon volume, which was smaller than the other three catheters. The Spectramed catheter had the largest balloon volume, which was larger than two of the other three catheters.

Air volume at the loss of resistance differed among the different catheters, but was constant for each catheter. This suggests that the injected air volume at the loss of resistance which can be established prior to catheter insertion can be used to determine the onset of balloon inflation. Our finding was similar to the study by Hardy $e t$ $a l .{ }^{3}$ in which the opening volume (the critical volume in their paper) without a variance was reported, but contrary to the finding by McDonald et al. ${ }^{2}$ In their study, the balloon did not expand with a standard injection volume. They suggested that it would be inaccurate to use the volume of injected air as the indicator of balloon expansion.

In order to avoid pressure-induced balloon rupture, Connors et al. ${ }^{6}$ recommended that the balloon be inflated with no more than $0.75 \mathrm{ml}$ of air. Our study, as well as Hardy's, showed the opening volume to be 0.7 to $1.0 \mathrm{ml}$, depending on the brand of catheter used. The balloons barely inflate with $0.75 \mathrm{ml}$ of air, and without balloon inflation the advantage of using of flow-directed PA catheter insertion will be lost.

The study using glass tubes was designed to mimic the intra-balloon pressure and volume relationship in the wedged position. Though the results obtained using the non-distensibility of glass tubes cannot be extrapolated to in vivo pulmonary arteries, the intra-balloon pressurevolume relationship in the same restricted diameters can be compared. The pressure obtained in the Edwards catheter when $1.5 \mathrm{ml}$ of air was injected in the $2.8 \mathrm{~mm}$ diameter tube was lower than that in the Abbott and Spectramed catheters, but there was no statistically significant difference between the Edwards and Arrow catheters. The Arrow catheter had the smallest final balloon volume compared with the other three catheters when $1.5 \mathrm{ml}$ of air was injected, suggesting that the tip of the Arrow catheter might migrate to a smaller, more distal vessel. However, the intra-balloon pressure obtained when it was inserted into the $2.8 \mathrm{~mm}$ glass tube was the second lowest among the tested catheters, which suggests the risk of pressure caused PA rupture is comparable with other catheters. The Spectramed catheter, which has the largest balloon volume, recorded the highest intra-balloon pressure when it was inserted into the smallest glass tube. The pressure obtained in the $2.8 \mathrm{~mm}$ diameter glass tube was comparable to the lowest rupturing pressure of 975 $\mathrm{mmHg}$ reported by Hardy et al. in the cadaver. In their study, the balloon was inflated with $1.5 \mathrm{ml}$ of liquid. ${ }^{4}$ In the same study none of the tested PA catheters ruptured when $1.5 \mathrm{ml}$ of air was used to inflate the balloon; however, they did not mention the position of the tip of the catheter which is clinically as important as its balloon pressure. Minimum rupturing pressures have not been reported when the balloon is inflated by $1.5 \mathrm{ml}$ of air.

There are several potential factors influencing PA rupture such as pulmonary hypertension, patient's age and use of anticoagulants, etc. ' However, this study suggests that if the balloon pressure continues to increase or the pretested loss of resistance volume is exceeded without a loss of resistance, the catheter should be suspected of being wedged, and no more air should be injected.

In summary, the results of the present study have implications of clinical importance. The peak intraballoon pressure recorded immediately before loss of resistance was felt in the inflating syringe. Unless the tip of the catheter was already in the peripheral PA, the peak intra-balloon pressure was not the pressure exerted on the pulmonary artery wall. Air should be injected slowly, preferably over at least three seconds. The slower the rate of injection, the lower were the peak pressure and the injection volume at the peak pressure. Air volume at the loss of resistance differed among the different catheters, but was constant for each catheter. A loss of resistance volume should be determined prior to catheter insertion, and this can be used as an indicator of instantaneous balloon inflation. Abbott, Edwards and Spectramed catheters have similar characteristics of inflation volume and intra-balloon pressure. The opening intra-balloon pressure, plateau pressures and the injected volume at the balloon opening were higher with the Arrow catheter than with the other three catheters although the balloon volume 
when $1.5 \mathrm{ml}$ of air was injected was the smallest among the tested catheters.

\section{References}

1 Barash $P G$, Nardi D, Hammond G et al. Catheterinduced pulmonary artery perforation, mechanisms, management, and modifications. J Thorac Cardiovasc Surg 1981; 85: 5-12.

$2 M c$ Donald $D H$, Zaidan JR. Pressure-volume relationships of the pulmonary artery catheter balloon. Anesthesiology $1983 ; 59: 240-3$.

3 Hardy JF, Taillefer J. Inflating characteristics of SwanGanz catheter balloons: clinical considerations. Anesth Analg 1983; 62: 363-34.

4 Hardy JF, Morissette M, Taillefer J, Vauchlair, R. Pathophysiology of rupture of the pulmonary artery by pulmonary artery balloon-tipped catheters. Anesth Analg 1983; 62: 925-30.

5 Durbin CG Jr. The range of pulmonary artery catheter balloon inflation pressures. Journal of Cardiothoracic Anesthesia 1990; 4: 39-42.

6 Connors JP, Sandza JG, Shaw RC, Wolff GA, Lombardo $J A$. Lobar pulmonary hemorrhage. An unusual complication of Swan-Ganz catheterization. Arch Surg 1980; 115 : 883-5. 